\title{
Os Estudos Sobre François Delsarte no Brasil e a Nota Biográfica de Delaumosne
}

\author{
José Rafael Madureira \\ Universidade Federal de Alagoas/UFAL, Maceió, Brasil \\ E-mail: joserafaelmadureira@gmail.com
}

Resumo

Tradução e notas do primeiro registro biográfico sobre François Delsarte escrito por um dos seus mais destacados discípulos, o Abade Delaumosne. Esse texto foi publicado na introdução do livro Pratique de l'Art Oratoire de Delsarte (1874) e traduzido para o inglês por Frances Shaw em 1893. É importante destacar que as informações apresentadas por Delaumosne foram integralmente utilizadas em duas obras centrais da historiografia da dança: Delsarte System of Dramatic Expression (Geneviève Stebbins, 1885) e Every Little Movement, a book about François Delsarte (Ted Shawn, 1954). Esta tradução é precedida de uma apresentação cronológica da produção acadêmica brasileira e internacional sobre Delsarte e sua obra.

Palavras-chave

Delaumosne. François Delsarte. Biografia. Tradução.
Abstract

Translation and notes of the first biographical note written about François Delsarte by one of its most prominent disciples, the Abbot Delaumosne. The note was published in the book Pratique de l'Art Oratoire de Delsarte (1874) and translated into English by Frances Shaw in 1893. It should be noted that the information presented by Delaumosne were utilized in two central works of dance historiography: Delsarte System of Dramatic Expression (Genevieve Stebbins, 1885) and Every Little Movement, a book about François Delsarte (Ted Shawn, 1954). This translation is preceded by a chronological presentation of the Brazilian and international academic production on Delsarte and his work.

Keywords

Delaumosne. François Delsarte. Biography. Translation. 
François Delsarte já não é um nome tão estranho aos estudantes e pesquisadores brasileiros da área de artes cênicas, embora exista ainda muito a ser investigado sobre esse tenor francês do século XIX e seu sistema, conhecido como Estética Aplicada. A obra de Delsarte é hermética, e não deve ser revisitada como relíquia arqueológica, mas experimentada no corpo, na voz e na cena.

O pensamento de François Delsarte não é inequívoco, equilibrando-se entre a metafísica e o racionalismo científico oitocentista. Parte dessa dificuldade, como se sabe, justifica-se pela escassez de registros por ele deixado. Delsarte publicou somente dois pequenos ensaios: Méthode Philosophique du Chant (1833) e Esthétique Appliquée, les sources de l'Art (1866), ambos publicados na versão original por Allain Porte (1992) e na versão em italiano por Elena Randi (1993).

Depois de sua morte, os discípulos Delaumosne, Angélique Arnaud e Alfred Giraudet publicaram respectivamente Pratique de l'Art Oratoire (1874), François Del Sarte: ses découvertes en esthétique, sa science, sa méthode (1882) e Mimique, Phisionomie et Gestes: Pratique d'après le Système de F. Del Sarte (1895), sendo que as duas primeiras obras foram traduzidas para o inglês por Francis Shaw e condensadas na publicação Delsarte System of Oratory (1893).

Em 1885, com base nos escritos originais de Delaumosne, Geneviève Stebbins publicou nos Estados Unidos Delsarte System of Dramatic Expression, um best-seller que conquistou seis consagradas edições. Depois de um intervalo de quase 70 anos, Ted Shawn publicou o notório Every Little Movement, a book about François Delsarte (1954), trazendo a Estética Aplicada novamente para o centro dos deba- tes sobre a formação dos artistas da cena.

O gênero teatral, até os anos de 1980, foi considerado de menor importância para a historiografia (Ropa, 1988), o que dificultou uma análise mais precisa dos vestígios deixados por Delsarte e seus discípulos, um conjunto de escritos que abarca os mais variados campos: metafísica, pedagogia, estética, interpretação dramática, dicção, oratória, moral. Esse quadro começou a se modificar com a divulgação dos estudos realizados pela historiadora italiana Eugenia Casini Ropa (1984; 1988) e pelos trabalhos de Allain Porte (1992) e Elena Randi (1993; 1996).

No Brasil, a redescoberta de François Delsarte aconteceu algum tempo depois, quando Delsarte deixou de aparecer somente nas notas de rodapé para assumir o eixo central de uma dissertação de mestrado defendida no Programa de Pós-Graduação em Educação, Linguagem e Arte da Unicamp (Madureira, 2002).

Em 2005, Every Little Movement, a book about François Delsarte foi traduzido para o francês por Annie Suquet, que ampliou consideravelmente o trabalho com 45 páginas de notas e fotografias inéditas. Importante ressaltar que essa tradução foi prefaciada por Nancy Lee Ruyter.

Em 2006, Matteo Bonfitto apresentou em O ator compositor uma breve descrição dos princípios da Estética Aplicada de Delsarte. Nesse mesmo ano, defendeu-se mais uma dissertação com base nos estudos de Delsarte no Programa de Pós-Graduação em Artes da Unicamp (Andrade, 2006).

Em 2009, na França, um substancial doutorado em história contemporânea foi defendido por Franck Waille, um trabalho com mais de mil páginas sobre a vida e obra de Delsarte. 
Ainda em 2009, publicou-se na Revista Imaginário da USP o primeiro artigo biográfico sobre Delsarte e os princípios estético-pedagógicos da Estética Aplicada (Madureira, 2009).

Em 2011, o bicentenário de nascimento de Delsarte foi celebrado na França através de um colóquio internacional que contou com a presença de Elena Randi, Allain Porte, Nancy Lee Ruyter e Franck Waille. No mesmo ano, a Revista Repertório dedicou a Delsarte a seção Persona, apresentando, entre outros artigos, a tradução inédita do ensaio Método Filosófico do Canto, publicado por Delsarte em 1833. Ainda em 2011, Eliza Teixeira de Souza defendeu sua dissertação de mestrado no Programa de Pós-graduação em Artes da UnB articulando o sistema de Delsarte com a Rítmica de Jaques-Dalcroze.

No ano seguinte, em 2012, a Revista Brasileira de Estudos da Presença publicou o dossiê A pedagogia de François Delsarte, que trouxe textos originais de Elena Randi, Nancy Lee Ruyter e Franck Waille, entre outros, além da tradução de um manuscrito inédito de Delsarte cuidadosamente selecionado por Waille.

Em 2014, a editora Perspectiva publicou a obra $A$ dança e o agit-prop: os teatros não teatrais e a cultura alemã do início do século $X X$, um trabalho de Eugenia Casini Ropa publicado originalmente em 1988 e que traz a instigante Nota sobre François Delsarte (p. 95-110).

Ao final de 2017, Lourenço e Vitello publicaram na Revista Cena mais um trabalho fundamentado na Estética Aplicada de Delsarte e, no ano seguinte, na mesma revista, Franck Waille publicou mais um artigo original baseado em sua tese de doutorado.

Todo esse processo contínuo de retorno às ideias de Delsarte parece ser um indicativo de um interesse manifesto da parte dos pesquisa- dores brasileiros e estrangeiros por uma obra original e igualmente magnética que provoca nos leitores contemporâneos o mesmo arrebatamento que hipnotizou grandes nomes da arte e da cultura oitocentista que frequentavam os Cursos de Estética Aplicada realizados entre 1840 e 1870 na capital francesa (Maria Malibran, Henriette Sonntag, Jules Lefort, Louis Gueymard, Willian Charles Macready, Eugène Delacroix, Alexandre Dumas, Georges Bizet, Gioacchino Rossini, Aphonse de Lamartine, Theóphile Gautier e Richard Wagner).

Com o intuito de contribuir com a hermenêutica da Estética Aplicada, apresentamos em seguida a tradução do primeiro registro biográfico sobre Delsarte escrito por um dos seus mais destacados discípulos, o Abade Delaumosne. Esse fragmento foi publicado na introdução do livro Pratique de l'Art Oratoire de Delsarte (1874) como também na versão em inglês de Frances Shaw (1893).

É importante destacar que as informações apresentadas por Delaumosne foram integralmente utilizadas em duas obras centrais da historiografia da dança: Delsarte System of Dramatic Expression (Geneviève Stebbins, 1885) e Every Little Movement, a book about François Delsarte (Ted Shawn, 1954).

Pouco se sabe sobre Delaumosne excetuando-se o breve encontro que Stebbins teve com ele, curiosamente da igreja Santa Geneviève, e que foi descrito em seu best-seller.

Delaumosne redigiu essa pequena nota biográfica em declarado tom devocional talvez com a intenção de também vangloriar a si mesmo, pois ele se apresenta como verdadeiro herdeiro do legado de Delsarte, uma posição violentamente rejeitada pelos filhos deste. Alguns episódios descritos são recorrentes nos trabalhos dos historiadores contemporâ- 
neos, outros, parecem ser apenas peripécias ficcionais criadas por seu autor. Todavia, não se pode negar que François Delsarte foi uma figura marcante cuja obra atravessou o tempo com o mesmo vigor que ele exibiu nos escritos publicados na juventude.

François Delsarte: uma biografia (Delaumosne, 1874) ${ }^{1}$

François Delsarte nasceu no dia 11 de novembro de 1811 em Solesmes, uma pequena cidade na Região Norte. Seu pai, destacado médico e autor de invenções diversas, poderia ter conquistado fortuna, mas, muito pouco preocupado com o futuro, morreu numa condição que beirava a miséria. Delsarte foi enviado à Paris em 1822, onde foi aprendiz de um pintor de porcelana.

Conduzido por seu gosto e aptidão para a música, em 1825 ele solicita e obtém a admissão no Conservatório na qualidade de pensionista $^{2}$. Ali esperava por ele uma grande provação que arruinou sua carreira, mas que foi um ganho para o seu gênio como artista e para sua fé. Ele foi colocado para fazer aulas de canto e técnica vocal nas quais, muito rapidamente, pela falta de método e direção, ele perdeu a voz. O jovem aluno ficou inconsolável, mas, sem insultar sua dor, podemos dizer: feliz perda que nos valeu o primeiro legislador da arte da oratória!

Malgrado essa irreparável perda, ele não se

1 Delaumosne. Pratique de l'Art Oratoire de Delsarte. Paris: Joseph Albanel, 1874, p. i-ix. Tradução e notas de José Rafael Madureira e revisão técnica de Isabelle Alcaraz.

2 Conforme Porte (1992), Pe. Bambini foi responsável em garantir à Delsarte essa oportunidade de estudos no consagrado Conservatório Real de Música e Declamação de Paris, cuja estrutura didático-pedagógica foi alvo de severas críticas da parte de Delsarte. deixou sucumbir à nefasta fortuna sem pedir uma última palavra. Ele apresenta-se ao concurso de 1829. Ele não poderia conquistar o êxito com sua voz danificada, mas recebeu cumprimentos compensadores ${ }^{3}$. O célebre Nourrit ${ }^{4}$ Ihe disse: "Eu vos indiquei para o primeiro prêmio, e seguramente meus filhos terão somente a vós como mestre de canto". Ele sustentou sua palavra. "Coragem!", Ihe falou por sua vez Madame Malibran ${ }^{5}$ ao apertar-Ihe a mão, "Vós sereis um dia um grande artista".

Todavia, Delsarte compreendeu que, desprovido de voz, seria preciso renunciar ao teatro e, resignando-se à impossibilidade física, ele sacrificaria a carreira como ator para tornar-se um professor.

Depois de ter naufragado sobre uma nau sem piloto e sem bússola, ele dedicou-se de todo coração à busca pelas leis de uma arte que, antes dele, vivia somente de caprichos e inspirações pessoais.

Depois de muitos anos de trabalho, ele conseguiu descobrir e formular as leis constitutivas de todas as artes, e graças a ele, hoje, a ciência estética tem a mesma precisão das ciências matemáticas.

Ele teve numerosos alunos, sendo que a maior parte deles conquistou destaque nas mais variadas carreiras públicas. No púlpito: o Pe. Monsabré ${ }^{6}$, seu fiel amigo e brilhante discípulo; na tribuna: Keller ${ }^{7}$, eloquente e generoso

3 O concurso de canto foi realizado em 1828 e Delsarte conquistou o segundo lugar.

4 Nourrit, Adolphe (1802-1839): Tenor francês. Foi protagonista em inúmeras encenações realizadas pelo Opera de Paris.

5 Malibran, Maria (1808-1836): Mezzo-soprano francesa de origem espanhola.

6 Monsabré, Jacques-Marie-Louis (1827-1907): Padre dominicano e renomado pregador francês.

7 Keller, Emile (1828-1909) considerado o pai da Alsácia em luto. 
defensor da causa católica, pai da Alsácia em luto ${ }^{8}$; no teatro: a célebre Sra. Sontag ${ }^{9}$, que o escolheu como professor quando desejou interpretar a música de Glück; Henry Lasserre ${ }^{10}$, esse brilhante advogado da Notre-Dame de Lourdes que não deveria se lamentar das frequentes conversações com nosso eloquente professor.

Homem de coração e inteligência, pleno de amenidade, despretensioso, Delsarte teve numerosos amigos entre as ilustres figuras contemporâneas.

Rachel ${ }^{11}$ inspirava-se com os conselhos de quem, para ela, era como um guardião do fogo sagrado. Ele foi vivamente solicitado para ser o seu interlocutor no Teatro-Francês: malgrado as mais belas ofertas, ele recusou essa honra por delicadeza religiosa.

Senhora de Girandin (Delphine Gay) ${ }^{12}$, conhecida como a Musa da Pátria, lamentava-se de não vê-lo com maior frequência em seus salões, época em que eram considerados um espaço de encontro da intelectualidade científica. Mais de uma vez ele foi convidado para os saraus literários do Colégio de Juilly; e sob o charme de sua dicção, os alunos sentiam-se inflamados de um novo ardor pelos estudos.

O Mons. Sibour ${ }^{13}$ o tinha em grande esti-

8 Alusão à guerra Franco-Prussiana de 1870, que provocou um verdadeiro êxodo dos habitantes da Alsácia.

9 Sontag, Henriette (1806-1854) : Soprano alemã. Frequentou os cursos de Estética Aplicada ministrados por François Delsarte em Paris em meados do século XIX.

10 Lasserre, Joseph-Henri (1828-1900): Advogado, jornalista e escritor católico francês.

11 Raquel, Felix (1821-1858): Atriz francesa.

12 Girandin, Delphine de (1804-1855): Escritora francesa, consagrou-se com os artigos publicados para o jornal La Presse sob o pseudônimo de Charles de Launay, ou simplesmente Visconde de Launay, um trabalho posteriormente organizado e publicado em 1843 como Lettres Parisiennes.

13 Sibour, Marie-Dominique-Auguste (1792-1857): Padre ma e afeição, convidando-o a juntar-se a ele à mesa. Foi justamente no salão desse arcebispo amigo das artes que Delsarte obteve o seu mais belo triunfo.

Todas as sumidades da ciência encontravam-se reunidas. A conversação desencadeava-se de um modo que, sem ofender ninguém, Delsarte encontrou um meio de propor um desafio, a partir destes dois versos de Racine:

$$
\begin{gathered}
\text { A onda se aproxima, quebra, e } \\
\text { vomita aos nossos olhos, } \\
\text { numa torrente de espuma, um } \\
\text { monstro furioso }{ }^{14} \text {. }
\end{gathered}
$$

Poderiam me dizer a palavra mais potente e de mais elevado valor? Cada um refletiu, pesquisou e disse a palavra escolhida. Todas as palavras são pronunciadas alternadamente, excetuando-se apenas uma, a conjunção e... Ninguém considerou isso.

Então Delsarte levanta-se e, com um tom calmo e modesto, mas triunfante, diz a todos: "A sílaba de maior valor, a palavra mais potente, é a única que vós deixastes escapar; é a conjunção e cujo sentido evidentemente elíptico vos deixa numa apreensão daquilo que deve chegar". Todos se admitem vencidos, e aplaudem o artista vencedor.

Donoso Cortez ${ }^{15}$ adorava comunicar a ele suas ideias. No dia em que Delsarte cantou diante dele o Dies Iræ ${ }^{16}$, o ilustre filósofo, assaltado por uma emoção religiosa, reclamou esse canto para o seu funeral. Delsarte prome-

\footnotetext{
francês, engajado arcebispo de Paris; foi assassinado na revolução de 1848 .
}

14 Versos de Terâmeno para Teseu, Cena VI da tragédia Fedra (1677). Texto original: "L'onde approche, se brise, et vomit à nos yeux,/Parmi des flots d'écume, un monstre furieux".

15 Cortez, Donoso (1809-1853): Parlamentar, diplomata e escritor espanhol.

16 Dies Iræ de um réquiem escrito por Delsarte para canto e piano. 
teu, e foi fiel a sua promessa.

Convidado à corte de Louis-Philippe ${ }^{17}$, ele responde: "Eu não sou um bobo da corte". Propõe-lhe uma generosa compensação, ele responde: "Eu não vendo meus amores". Sobre a observação de que seria uma festa que o duque d'Orléans gostaria de oferecer a seu pai, ele aceita, mas estipula três condições: " $1^{\mathrm{a}}$. Serei o único cantor; $2^{\mathrm{a}}$. Terei como acompanhamento somente o coro do Opera; $3^{a}$. Não receberei qualquer pagamento".

Delsarte superou a si mesmo. Louis-Philippe envolveu-o de considerações, ao ponto que o Sr. Ingres ${ }^{18}$ não pode deixar de dizer: "Diríamos, na verdade, que é Delsarte o rei da França".

A reputação de Delsarte havia ultrapassado a fronteira, o rei de Hanover ${ }^{19}$ enviou-Ihe a maior artista de seu reino ${ }^{20}$. O rei, ao julgar que a ilustre viajante não havia perdido seu tempo, desejou recompensar o professor e, sob um envelope assinado pela sua mão real, entregou-lhe a Medalha de Honra das Ciências e Artes de Hanover. Mais tarde ele recebeu desse mesmo rei a Cruz dos Cavaleiros da Ordem dos Guelfos. $\left(^{*}\right)$

Não saberíamos coroar com maior precisão essa nomenclatura que nomeando

Raymond Brucker ${ }^{21}$, alter ego do excelente Delsarte, seu bom e fiel gênio.

Não foi somente através da boca de seus

17 Louis-Philippe ou Duque de Orleans (1793-1830): Rei da França entre 1830 e 1848.

18 Ingres, Jean-Aguste-Dominique (1780-1867): Pintor e desenhista francês.

19 Ernest Augustus I (1771-1851): Rei de Hanover entre 1837 a 1851.

20 Possivelmente uma diva, enviada para estudar o bel canto com Delsarte.

21 Brucker, Raymond Philippe Auguste (1800-1875): Escritor francês. ouvintes que Delsarte foi ovacionado, seu mérito foi celebrado nas revistas científicas, Laurentie $^{22}$, Riancey ${ }^{23}$, Lamartine ${ }^{24}$ e Théophile Gautier $^{25}$ a ele atribuíram os mais pomposos elogios; seu nome desde então conquistou a posteridade. Escutemos o Sr. Laurentie:

Eu o ouvi recitar, uma noite, o sonho de Ifigênia ${ }^{26}$, que o público lhe havia solicitado. A sala estava comovida, a perder o fôlego diante daquela voz débil e, contudo, soberana. Todos se sentiram subjugados pelo arrebatamento diante de tal encantamento. Nada de magia ou ilusão teatral. Ifigênia, era um professor de fraque negro; a orquestra, um piano articulando aqui e lá inesperadas modulações ${ }^{27}$; ali residia toda a sua potência... e a sala estava emudecida, os corações acelerados, lágrimas escorriam dos olhos; e depois, quando a récita chegou ao fim, gritos de entusiasmo elevavam-se como se Ifigênia, em pessoa, tivesse vindo contar seus horrores ${ }^{28}$.

Depois de ter colhido uma tão generosa coIheita de louros, ficou decidido que Delsarte

22 Laurentie, Pierre Sabastien (1793-1876): Jornalista, escritor e pensador francês.

23 Riancey, Henri-Léon Camusat de (1816-1979): Parlamentar e escritor francês.

24 Lamartine, Aphonse (1790-1869): Poeta francês. Frequentou os cursos de Estética Aplicada ministrados por François Delsarte em Paris em meados do século XIX.

25 Gautier, Théophile (1811-1872): Poeta e novelista francês. Frequentou os cursos de Estética Aplicada ministrados por François Delsarte em Paris em meados do século XIX.

26 Possível referência a ária O Malheureuse Iphigénie da ópera Ifigênia em Tauris de Glück, compositor de sua predileção. Apesar de suas limitações vocais, Delsarte demonstração técnica em seus cursos de Estética Aplicada, interpretando trechos de árias escritas em diversos registros.

27 Ao piano, Rosália Adrien, instrumentista virtuose e professora de solfejo na Escola Real de Música e Declamação de Paris. Delsarte a desposou em 1833 e, desde então, tornou-se a sua companheira fiel e inestimável colaboradora de seus cursos de Estética Aplicada.

28 Conforme Randi (1993, p. 137), a surpreendente narrativa também foi descrita por Adolphe Guéroult em ocasião do necrológio de Delsarte. 
havia vivido o suficiente. Ao chegar ao seu $60^{\circ}$ aniversário, ele foi acometido de uma hipertrofia no coração que deixou em ruínas essa rica organização.

Não mais existia o artista de movimentos tão plásticos, tão graciosos, expressivos e harmoniosos. Não mais existia o pensador de profundas e luminosas ideias.

Mas, no interior dessas ruínas físicas e morais, o sentido cristão nada perdeu de sua máscula e doce energia.

Apologista dos sacramentos, que ele recebeu nos dias de santidade, ele os reclamou no instante do perigo. Incontáveis vezes ele recebeu o sacramento de amor, cuja virtude ele ensinava com tanta maestria.

Enfim, depois de ter vegetado durante vários meses, num estado que não era nem de vida nem de morte, acompanhado por sua piedosa esposa e seus filhos que choravam e rezavam, ele entregou sua alma a Deus, no dia 20 de julho de 1871.

Além de suas obras de música e canto ${ }^{29}$, Delsarte nunca conseguiu decidir-se a escrever. $\left({ }^{\star *}\right)$

Eu preciso salvar do esquecimento a mais maravilhosa concepção dessa inteligência superior, seu Curso de Estética Oratória. Ouso prometer ser seu fiel intérprete. Se fosse preciso me desculpar por não ter declinado à tão delicada tarefa eu responderia: dirijo-me a uma classe de leitores que saberão apreciar os motivos de minha determinação. O mérito do autor, a honra de sua família, a alegria de seus numerosos amigos, o interesse da ciência e a amizade me impõem o dever de não colocá-lo

29 Além do trabalho como compositor, Delsarte realizou uma minuciosa compilação de peças vocais antigas, os Archives du Chant, muito elogiada por Saint-Saëns pela beleza tipográfica, pela precisão e bom gosto e pelo respeito às versões originais dos compositores, uma espécie de edição Urtext. debaixo do alqueire, mas sim para coloca-lo sobre o candeeiro, uma luz que lançou um briIho tão vívido, enriquecendo as artes com um esplendor renovado ${ }^{30}$.

Notas originais de Delaumosne

$\left(^{*}\right)$ No mesmo dia de nossos primeiros desastres ${ }^{31}$, em 4 de setembro de 1870, ele recebeu a cruz dos Cavaleiros da Legião de Honra, por um decreto assinado pela imperatriz regente, sob a proposição de Maurice Richard, então ministro das Belas Artes.

$\left({ }^{* *}\right)$ Recentemente, a Sra. Delsarte descobriu e me confiou alguns fragmentos de um trabalho que o eminente artista havia empreendido pouco tempo antes de sua última doença. Cinquenta páginas de uma obra intitulada Episódios Reveladores $^{32}$; vinte páginas de um Tratado sobre os Atributos da Razão ${ }^{33}$. Esses são os frutos tardios dessa rica inteligência. Publicarei estas preciosas páginas que, não tenho dúvida, serão acolhidas como o último canto do cisne.

\section{Referências}

ANDRADE, Carolina Romano de. O gestual humano e o barroco mineiro à luz dos estudos de François Delsarte. 2006. 146 f. Dissertação (Mestrado em Artes). Campinas: Instituto de Artes da UNICAMP, 2006.

ARNAUD, Angélique. François Del Sarte: ses découvertes en esthétique, sa science, sa méthode. Paris: Librairie Charles Delagrave, 1882.

30 Observa-se neste parágrafo uma alusão ao Evangelho segundo Mateus: "Vós sois a luz do mundo. Não se pode esconder uma cidade situada sobre uma montanha nem se acende uma luz pra coloca-la debaixo do alqueire, mas sim para coloca-la sobre o candeeiro, a fim de que brilhe a todos os que estão em casa. Assim, brilhe vossa luz diante dos homens, para que vejam as vossas boas obras e glorifiquem vosso Pai que está nos céus." (Mt 5:15).

31 Referência à invasão da Prússia.

32 O manuscrito foi transcrito e publicado In PORTE, 1992, p. $55-88$.

33 O manuscrito foi transcrito e publicado In PORTE, op. cit., p. 247-57. 
BONFITTO, Matteo. O Ator Compositor: as ações físicas como eixo - de Stanislávski a Barba. 2a ed. São Paulo: Perspectiva, 2006.

DELAUMOSNE. Pratique de l'Art Oratoire de Delsarte. Paris: Joseph Albanel, 1874.

Delsarte System of Oratory. Tradução e organização de Francis Shaw. New York: Edgar Werner, 1893.

DELSARTE, François. Método Filosófico do Canto. Tradução de José Rafael Madureira. Revista Repertório, Salvador, n. 16, 2011, p. 174177. Disponível em: <https://portalseer.ufba. br/index.php/revteatro/article/view/5401>. Acesso em 24/09/2018.

Manuscritos. Tradução de Márcio Müller. Revista Brasileira de Estudos da Presença, Porto Alegre, v. 2, n. 2, p. 470-478, jul./ dez. 2012. Disponível em: <https://seer.ufrgs. br/presenca/article/view/29476>. Acesso em 10/07/2018.

GIRAUDET, Alfred. Mimique, Phisionomie et Gestes: Pratique d'après le Système de F. Del Sarte. Paris: Ancienne Maison Quantin, 1895.

LOURENÇO, Robson.; VITIELLO, Júlia Ziviani. Dissecação Simbólica do Corpo: os estudos anatômicos de François Delsarte e suas reverberações na percepção do movimento, a partir de um recorte sobre a dança moderna americana. Revista Cena, Porto Alegre, n. 22, p. 128-141, jul./out. 2017. Disponível em: <http:// seer.ufrgs.br/cena>. Acesso em 14/08/2018.
MADUREIRA, José Rafael. François Delsarte: personagem de uma dança (re) descoberta. Dissertação (Mestrado em Educação). 2002. 244 f. Campinas: Faculdade de Educação da UNICAMP, 2002.

A Estética Aplicada de François Delsarte: entre memórias e esquecimentos. Revista Imaginário, São Paulo, ano XIII/IV, n.17/18, 2009, p.319-345. Disponível em: <https://drive.google.com/file/d/1D3IYWhG-WGex-9zPbxxlwvc3tsQb7oqQ/view>. Acesso em 20/05/2018.

PORTE, Allan. François Delsarte: une anthologie. Paris: Édition IPMC, 1992.

RANDI, Elena. (org.). François Delsarte, le leggi del Teatro - II pensiero scenico del precursore della danza moderna. Roma: Buzone Editore, 1993.

- Il Magistero Perduto di Delsarte: dalla Parigi romantica alla Modern Dance. Roma: Esedra, 1996.

REVISTA BRASILEIRA DE ESTUDOS DA PRESENÇA (UFRGS). Dossiê: A pedagogia de François Delsarte. Rio Grande do Sul, v. 2, n. 2, Jul./Dez. 2012, p. 294-478.

ROPA, Eugenia Casini. François Delsarte: o gli improbabili tragitti di un insegnamento. Bolonha, Quaderni di Tatro, n. 23, Fev. 1984, p.7-17.

Nota su François Delsarte In: CASSINI ROPA, La danza e l'agitprop: I teatri-non-teatrali nella cultura tedesca del primo Novecento. Bolonha: II Mulino, 1988. p.107-122. 
La danza e l'agitprop: I teatri-non-teatrali nella cultura tedesca del primo Novecento. Bolonha: II Mulino, 1988.

A dança e o agit-prop: os teatros não teatrais e a cultura alemã do início do século XX. Tradução de Matteo Bonfitto, Michele Schiocchet e Yedda Chaves. São Paulo: Perspectiva, 2014.

SHAWN, Ted. Every Little Movement: a book about François Delsarte. New York: M. Witmark \& Sons, 1954.

Chaque petit mouvement: à propos de François Delsarte. Tradução e notas de Annie Suquet. Bruxelles: Éditions Complexe, 2005.

SOUZA, Elisa Teixeira de. O sistema de François Delsarte, o método de Émile Jaques-Dalcroze e suas relações com as origens da dança moderna. Dissertação (Mestrado em Artes). 2011. 273 f. Departamento de Artes da Universidade de Brasília, 2011.

STEBBINS, Genevieve. The Delsarte System of Dramatic Expression. New York: Edgar S. Werner, 1885.

WAILLE, Franck. Corps, arts et spiritualité chez François Delsarte: des interaction dynamiques. Tese (Doutorado em história contemporânea). 2009. 1.038 f. Lyon: Université Jean-Moulin Lyon 3, 2009.
- Corpo, Artes e Espiritualidade no Trabalho de François Delsarte (1811-1871): uma dinâmica da educação somática expressiva. Tradução de Leela Alaniz. Revista Cena, Porto Alegre, n. 24, p. 3-19, jan./abr. 2018. Disponível em: <http://seer.ufrgs.br/cena>. Acesso em 14/08/2018.

Recebido: 04/11/2018

Aprovado: 11/01/2019 